УДК 821.161 .1

\title{
Ф.В. Макаричев
}

\section{ПРОФЕТИЗМ ХУДОЖЕСТВЕННЫХ УСТАНОВОК Ф.М. ДОСТОЕВСКОГО И ЕГО ВЛИЯНИЕ НА ПОЭТИКУ ОБРАЗОВ}

В статье выявляется взаимосвязь и взаимообусловленность профетических интуиций Ф.М. Достоевского с особенностями методологии и, шире, природой художественного творчества писателя. Проводятся параллели между творческими установками Достоевского и Шекспира в рецепции философских критиков и литературоведов начала XX в. Это позволяет сделать вывод о том, что профетизм Достоевского можно считать выражением стихийноиндивидологических установок в изображении героев, ориентацию писателя на изображение не типа, а попушкински сложной, противоречивой индивидуальности, корни которой уходят в шекспировскую традицию.

Ключевые слова: поэтика, профетические установки, шекспиризм, художественный образ, трагедия, индивидология.

DOI: $10.35634 / 2412-9534-2021-31-2-283-290$

Определенную сложность в опознании социально-психологической репрезентативности художественных образов Достоевского представлял для современников особый характер творческих установок писателя, его профетических интуиций. Поясняя сущность своего «фантастического реализма», Достоевский писал: «Нам знакомо одно лишь насущное видимо-текущее, да и то по наглядке, а концы и начала - это все еще пока для человека фантастическое» [5, т. 23, с. 145].

В письме А.Н. Майкову Достоевский в полемически-заостренной форме определил свое творческое credo так: «Совершенно другие я понятия имею о действительности и реализме, чем наши реалисты и критики. Мой идеализм - реальнее ихнего. $<\ldots>$ Ихним реализмом - сотой доли реальных, действительно случившихся фактов не объяснишь. А мы нашим идеализмом пророчили даже факты» [5, т. 28, кн. 2, с. 329]. То, что эти высказывания Достоевского - не отвлеченные рассуждения о своих художественных принципах, но выражение его ценностных ориентаций в искусстве, можно утверждать, судя по той обостренной реакции недопонимания, которую проявляли многие современники писателя.

Примечательно, что такое видение Достоевским эстетической перспективы получило новую интерпретацию в начале XX в. Комментируя высказывание писателя о реализме, Л. Пумпянский делает его провозвестником эстетической эсхатологии. В этой отчетливо проступившей пророческой сущности «поэзии Достоевского» ученый усмотрел разрушение основополагающих принципов искусства. В работе «Достоевский и античность», характеризуя поэтику писателя в контексте культурно-исторического развития античной трагедии, исследователь определяет «поэзию» художника логическим завершением эстетического апокалипсиса: «Начавшись с сомнения Гамлета, внутри поэзии образовалась сила, самоорганизовавшаяся и готовая выступить из пределов вымысла. Когда Достоевский характеризовал себя знаменитыми словами: “мы нашим идеализмом предсказывали факты”, он очень верно понял главную черту своей поэзии (впрочем, и поэзии Пушкина и всей русской поэзии), именно дар дивинации, пророческой отгадки. Только дело было не в идеализме, а в том, что пророческий путь упреждения фактов был следствием разрушения поэтической системы. Здесь становится совершенно ясно, насколько далека поэзия Достоевского от сферы трагедии. Трагедия есть всегда п а м я т ь о событии, никогда п р о р о ч е с т в о о нем. $<\ldots>$ Трагедия есть последняя волна события, уже не реальная, а вполне фиктивная. Поэзия же Достоевского есть волна еще не бывшего события; вторая и следующие будут уже не в поэзии, а в реальности. Тема трагедии - некоторые фиванские средние века; тема Достоевского - некоторое еще не бывшее время. Одним словом, организованной памяти трагедии поэзия Достоевского противопоставляет организованное пророчество. Из этого неопровержимо следует, что Достоевский не есть трагический поэт: его слово не именует, не вспоминает, а предваряет. <...> Отсюда же следует, что тема "Братьев Карамазовых" не есть родовая тема в античном смысле этого слова. <...> Таким образом, коренная тема трагедии у Достоевского осела, косо положена, ибо убил тот, кто и сын и лакей. Одним углом осело отцеубийство, перейдя к побочному сыну, и вовсе осело, перейдя к лакею. Это не отцеубийство, а политическое убийство, террори- 
стический акт, акт вражды сословий. Не память о феодальной вражде, а пророчество о вражде классовой» $[18$, с. 524]. Такое символистское истолкование сущности «поэзии» Достоевского вполне органично в контексте эпохи и, вероятно, явилось следствием совпадения двух кризисов: политического (память о революционной катастрофе более чем свежа) и эстетического (кризис реализма и творческие поиски его преодоления). Характерно, что этот «дар дивинации, пророческой отгадки» Достоевского почти всегда актуализируется для читателей в переломные исторические моменты. Этим объясняется и повышенный интерес к творчеству писателя в России на рубеже 90-х гг. XX в. Однако ранее, в начале XX столетия, имело место их совпадение. То, что открывалось Пумпянскому в «поэзии» Достоевского в эпоху больших перемен, могло производить иные впечатления на современников писателя лишь в канун этих изменений.

Так, М.Е. Салтыков-Щедрин, восхищаясь нацеленностью писателя на изображение будущего, в то же время выражал недоумение по поводу описываемых им «нигилистов»: «Он (Достоевский Ф.М.) не только признает законность тех интересов, которые волнуют современное общество, но даже идет далее, вступает в область предведений и предчувствий, которые составляют цель не непосредственных, а отдаленнейших исканий человечества. Укажем хотя на попытку изобразить тип человека, достигшего полного нравственного и духовного равновесия, положенную в основание романа “Идиот" < .. > И что же? несмотря на лучезарность подобной задачи, поглощающей в себе все переходные формы прогресса, г. Достоевский, нимало не стесняясь, тут же сам подрывает свое дело, выставляя в позорном виде людей, которых усилия всецело обращены в ту самую сторону, в которую, по-видимому, устремляется и заветнейшая мысль автора. Дешевое глумление над так называемым нигилизмом и презрение к смуте, которой причины всегда оставляются без разъяснения, - все это пестрит произведения г. Достоевского пятнами совершенно им несвойственными и рядом с картинами, свидетельствующими о высокой художественной прозорливости, вызывает сцены, которые доказывают какое-то уже слишком непосредственное и поверхностное понимание жизни и ее явлений. <..> С одной стороны, у него являются лица, полные жизни и правды, с другой - какие-то загадочные и словно во сне мечущиеся марионетки, сделанные руками, дрожащими от гнева...» [21, с. 413]. Не углубляясь в анализ утверждения М.Е. Салтыкова-Щедрина о совпадении «заветнейшей мысли» Достоевского и «нигилистов», которое нам представляется откровенным заблуждением, укажем лишь на тот несомненный факт, что Достоевский изобразил этих «нигилистов» в «Идиоте» намного «мягче», чем, например, М. Булгаков, непосредственно заставший продолжателей этого «направления», - в «Собачьем сердце». Что же касается художественного отношения Достоевского к «нигилизму» в целом, то оно, без сомнения, было несколько сложнее, чем это могло показаться М.Е. Салтыкову-Щедрину. Глубже всего, на наш взгляд, его охарактеризовал В. Розанов: «Что такое революция? На это вам отвечает Петруша Верховенский в "Бесах". Кушает холодную курицу, дожидаясь самоубийства своего приятеля Кириллова. "Однако же" (всякая диалектика начинается с "однако") еще что такое революция? Это и Раскольников. Ведь несомненно тоже он не бытовик, не человек определенного строя жизни, а революционер, хоть и в первой фазе своего бунта. Значит, и Верховенский, и Раскольников - вот что такое революция. Согласитесь, что тут нельзя сказать ни "да", ни "нет"; согласитесь, что здесь "да" и "нет" сплелись в чудовищное единство»; «Отрицательная, отвратительная личность Петруши Верховенского (псевдоним Нечаева) в "Бесах" уравновешивается или, скорее, возмещается целою группою лиц, менее подробно описанных, но, пожалуй, освещенных еще ярче, чем он... Это - Шатов и Кириллов. <..> . . с существом монашества в этих замечательных и памятных отроках была слита беспредельная анархичность, вытекавшая не из склонности к "дебошу", а из бесконечной индивидуальности в них, субъективности, интимности...» [19].

Взгляд Розанова как бы «скользит» от типа («нигилиста») к конкретному образу, т. е. воплощению этого нигилизма, и прозревает его глубокую и сложную индивидуальность. Это и есть одно из проявлений «художественной индивидологии» самого Достоевского, в данном случае - можно сказать, - индивидологии типа, т.к. последний реализуется через индивидуализированное углубление каждого представителя. Иными словами, тип мыслится как некий сплав своих противоречивых представителей. Все эти части оказываются связанными незримыми смысловыми нитями так, что лишь по одной из них невозможно заключать о целом.

Этот индивидологический принцип реализуется Достоевским практически повсеместно, на уровне любого по значимости образа. Одним из первых, кто обратил на это внимание, был Д.И. Писарев. В статье «Борьба за жизнь» [17], посвященной «Преступлению и наказанию», он отметил 
большое смысловое напряжение на уровне самораскрытия главных героев, их «заряженность» противоположными смысловыми токами, порождающими противоречивое восприятие. Ярче всего это проявляется в рассуждениях критика о поступке Сони Мармеладовой: «Как вы назовете ее за этот поступок: грязной потаскушкой, бросившей в уличную лужу святыню своей женской чести, или великодушной героиней, принявшей с спокойным достоинством свой мученический венец? Какой голос эта девушка должна была принять за голос совести - тот ли, который ей говорил: “Сиди дома и терпи до конца, умирай с голоду вместе с отцом, с матерью, с братом и с сестрами, но сохраняй до последней минуты свою нравственную чистоту”, - или тот, который говорил: “Не жалей себя, не береги себя, отдай все, что у тебя есть, продай себя, опозорь и загрязни себя, но спаси, утешь, поддержи этих людей, накорми и обогрей их хоть на неделю во что бы то ни стало”?» [17, с. 182]. И далее Д. Писарев признается в собственной неспособности отвечать на подобные вопросы. Даже осуждая в целом алкоголика-Мармеладова, критик, тем не менее, замечает: «Всего ужаснее в этой личности и в этой исповеди именно то, что Мармеладова невозможно презирать целиком, презирать так, чтобы к этому презрению не примешивалось никакого другого чувства» [17, с. 177].

В контексте этих читательских впечатлений, касающейся творческой методологии Достоевского, интересна позиция И.А. Гончарова. Сохранилось, как известно, два письма, в которых автор «Обломова» делился с Достоевским своими недоумениями по поводу понимания типа: «Вы сами говорите, что “зарождается” такой “тип”; простите, если я позволю заметить здесь противоречие: если зарождается, то еще это не тип. Вам лучше меня известно, что тип слагается из долгих и многих повторений или наслоений явлений и лиц, где подобия тех и других учащаются в течение времени и, наконец, устанавливаются, застывают и делаются знакомыми наблюдателю. Творчество < ..> может являться только тогда, по моему мнению, когда жизнь установится; с новою, нарождающеюся жизнию оно не ладит...» [2, с. 407-408]; «Под типами я разумею нечто очень коренное - долго и надолго устанавливающееся и образующее иногда ряд поколений» [2, с. 410]. Примечательно, что эти рассуждения И. Гончарова возвращают нас к замечаниям Л. Пумпянского о «классической трагедии» и «поэзии Достоевского».

К сожалению, ответных писем Ф.М. Достоевского И.А. Гончарову не сохранилось, об их характере можно судить лишь косвенно, по «Дневнику писателя» и черновым записям к романам. В этих высказываниях Достоевского, зачастую эмоциональных и усиленных слогом, отчетливо различимо стремление писателя отмежеваться от подобных «классических» представлений о типах: «Взять и то, наконец, что наши художники (как и всякая ординарность) начинают отчетливо замечать явления действительности, обращать внимание на их характерность и обрабатывать данный тип в искусстве уже тогда, когда большею частию он проходит и исчезает, вырождается в другой, сообразно с ходом эпохи и ее развития, так что всегда почти старое подают нам на стол за новое. И сами верят тому, что это новое, а не преходящее. $<\ldots>$ Но я все-таки выскажу, что только гениальный писатель или уж очень сильный талант угадывает тип современно и подает его своевременно; а ординарность только следует по его пятам, более или менее рабски и работая по заготовленным уже шаблонам» (Выделено мной. - Ф.М.) [5, т.21, С. 89].

Возможно, природа этого взаимного недопонимания двух писателей в вопросе интерпретации типа отражает глубокое различие в предметах изображения. Оно коренится в ориентации писателей на изображение разных социокультурных слоев - дворянского и разночинского. Отсюда акценты: тип патриархально-устоявшегося у Гончарова и тип формирующегося «той, переходной ко всему лучшему эпохи», «когда время вышло из своих суставов» у Достоевского. И тот, и другой тип в равной мере имеют право на существование в художественном пространстве и даже, как показывает практика, на сосуществование «под свалку времен». Получается, что культурные рефлексы глубоко инстинктивны, и человек, даже великий художник, не властен над ними. Проблема этой «межкультурной» коммуникации сказывается, например, в том, что образ разночинца-Базарова в изображении аристократа-Тургенева и образ представителя высшего культурного слоя, дворянина-Версилова в изображении разночинца-Достоевского оказываются в чем-то ущербными (это отмечает, например, Переверзев): художники над ними полностью не властны (а иногда и откровенно не знают, что с ними делать), характер и манеры поведения героев нет-нет да выходят за рамки художественной достоверности, не удовлетворяют «горизонтам ожидания» во всей широте.

Очевидно, за разницей в художественно-методологических установках двух великих писателей (если Достоевский был «одержим тоской по текущему», то Гончаров, скорее, - по утраченному, безвоз- 
вратно ушедшему в историческое прошлое («Обломов»)) угадывается нечто более существенное, глубинное. Возможно, это различие в творческой природе двух великих писателей. Впрочем, не только это. Достоевский был всегда в гуще литературной, публицистической жизни и даже, как мы знаем, однажды стал фигурантом громкого политического дела. Гончаров, судя по имеющимся свидетельствам, напротив, как бы сторонился этой «мирской» суеты. Можно сказать, что он придерживался консервативных взглядов и в искусстве, и в жизни: достаточно сравнить характер и круг читательских интересов Достоевского (см. Л.П. Гроссман «Поэтика Достоевского») и Гончарова (см., например, «Необыкновенная история»). Все это отразилось даже на характере взаимоотношений двух писателей. Что-то разводило этих великих современников, чтобы свести их на большем круге; причем не только свести, но и «столкнуть». Так, уже в 20 -ее гг. XX в. Энгельгардт делился своими опасениями по поводу столь сильной «одержимости» Достоевского «тоской по текущему», его злободневной заостренности на «своевременности и современности» [25]. Встреча таких масштабных и «разнонаправленных» русских писателей, как Достоевский и Гончаров, на столь коротком историческом промежутке времени - явление уникальное. Герои Достоевского и Гончарова (пожалуй, как и сами писатели) живут в разных исторических ритмах, а потому и развиваются в разных эстетических реальностях. И если поэзия Достоевского была пророчеством о мятежном грядущем, то поэзия Гончарова - прорицанием вечного, неизбывного. (Иначе и не объяснить предлагавшейся уже на пороге XXI в. темы для школьного сочинения: «Почему Обломов относится к вечным образам?») То, что Достоевский полагал о Шекспире, на наш взгляд, верно и по отношению к Гончарову: «Это без направления и вековечное и удержалось.

Это не простое воспроизведение насущного, чем, по уверению многих учителей, исчерпывается вся действительность.

Вся действительность не исчерпывается насущным, ибо огромною своею частию заключается в нем в виде еще подспудного, невысказанного будущего слова. Изредка являются пророки, которые угадывают и высказывают это цельное слово. Шекспир - это пророк, посланный богом, чтобы возвестить нам тайну о человеке, души человече<ской>» [т.11, с. 237]. Это отношение Достоевского к Шекспиру в очередной раз возвращает нас к рассуждениям Л. Пумпянского, а также актуализирует глубинные взаимосвязи поэтик и творческих методологий великих классиков русской литературы: Пушкина, Гоголя, Достоевского. «Шекспировский контекст» в творчестве Достоевского, понастоящему широкий и глубокий, постоянно привлекает внимание исследователей, тема эта поистине неисчерпаема $[8-11 ; 23 ; 24]$. Этот контекст был достаточно укоренен в русской литературе, а потому в читательский кругозор и лабораторию творческой мысли писателя мог войти уже обогащенным множеством творческих интерпретаций. Следует отметить, что основным «проводником» «шекспиризма» был Пушкин [6; 7].

В своей последней статье «О реализме Гоголя» Ю.М. Лотман отмечал: «Театральная традиция, сложившаяся к концу XVIII в., открывала перед драматургом одну из двух возможных дорог. Так называемая шекспировская традиция, которая завоевала себе одно из ведущих мест на театральной сцене, особенно в драме, создавала характер как единство противоположных и взаимоисключающих психологических черт. Сопоставляя так называемые Шекспировские и мольеровские традиции, Пушкин писал: «Лица, созданные Шекспиром, не суть, как у Мольера, типы такой-то страсти, такого-то порока; но существа живые, исполненные многих страстей, многих пороков; обстоятельства развивают перед зрителем их разнообразные и многосторонние характеры. У Мольера Скупой скуп - и только; у Шекспира Шайлок скуп, сметлив, мстителен, чадолюбив, остроумен. У Мольера Лицемер волочится за женою своего благодетеля - лицемеря; принимает имение под сохранение, лицемеря; спрашивает стакан воды, лицемеря. У Шекспира лицемер произносит судебный приговор с тщеславной строгостью, но справедливо; он оправдывает свою жестокость глубокомысленным суждением государственного человека; он обольщает невинность сильными, увлекательными софизмами, не смешною смесью набожности и волокитства. Анжело лицемер - потому что его гласные действия противуречат тайным страстям! А какая глубина в этом характере!»

Так называемая мольеровская традиция легла в основу комических характеров, в то время как «шекспировская» сделалась фундаментом предромантической драмы. Первая традиция создавала типические характеры, вторая - индивидуальные образы. Первая реализовывала уже известные зрителю театральные типы, вторая - создавала эти типы, первая иллюстрировала, вторая генерировала. Таким образом, эстетика первого типа доставляла зрителю радость узнавания, вторая - потрясала его неожиданностью» [12, с. 701-702]. 
Это рассуждение Ю.М. Лотмана о поэтике Гоголя, на наш взгляд, также актуализирует и глубокую взаимосвязь между художественным методом Достоевского и Шекспира. То, что Лотман относит к поэтике Гоголя - особенности характерологии и профетизм, - приложимо и к поэтике Достоевского. Но у Достоевского есть и другие «точки соприкосновения» с Шекспиром. В замечательной статье Г.Ф. Коган «Лекция Тарле “Шекспир и Достоевский”» [8] представлена подробная библиография на эту тему: «Сравнение Достоевского с Шекспиром - "знатоком человеческого сердца" началось еще при его жизни, когда появились первые главы "Преступления и наказания"» [22, с. 276]; в 1870-х гг. Достоевского современники прямо называли «учеником Шекспира» [14, с. 206]. Сравнение с Шекспиром «таланта такого роста, как Достоевский», счел вполне правомерным Н.К. Михайловский, сопоставивший в своей знаменитой статье «Жестокий талант» «некоторые художественные приемы того и другого при разработке одной и той же темы» [16, с. 114].

В дальнейшем сопоставления Достоевского с Шекспиром делались многими критиками, писателями и философами. В исследованиях литературоведов давались своды высказываний Достоевского о Шекспире [3, с. 91, с. 93], примеры многочисленных и нередко очень значительных реминисценций из шекспировских пьес в его произведениях [14, с. 583; с. 584; с. 590-597], выяснялось, какое место занимал Шекспир в творческом сознании Достоевского [11], анализировалось обращение Достоевского к Шекспиру в его творческих рукописях [20, с. 43].

Но, пожалуй, первым, кто посвятил теме «Шекспир и Достоевский» специальное исследование, был Е.В. Тарле, поставивший задачу выявить шекспировские традиции в творчестве Достоевского не только в отдельных образах, но во всем художественном методе писателя. Этой темой он занялся задолго до юбилейных Шекспировских дней. Посылая А.Г. Достоевской программу лекции и рассказывая ей о замысле своей будущей книги о Достоевском, Тарле писал: «Я коснусь главным образом не той стороны его деятельности, которой касались Страхов, Орест Миллер, Аверкиев и т.д., не политических и религиозных его воззрений, но его художественного психологического изобразительного гения» $[15$, с. 122].

К сожалению, эта книга Е.В. Тарле так и не вышла в свет. Сопоставительный анализ художественной психологии, а точнее даже психопатологии, насколько можно судить по косвенным свидетельствам о творческих планах Е.В. Тарле, безусловно, обогатил бы науку о Достоевском. Однако интерес к «шекспиризму» в творчестве Достоевского не исчерпывается и этой темой.

Примечательно, что Луначарский, критикуя Бахтина, даже ставил под сомнение его тезис о безусловном новаторстве Достоевского в создании полифонического романа, т.е. полифонизм как художественный принцип полагал творческим наследием Шекспира: «Не говоря о многочисленных позаимствованиях, переделках чужих пьес, не говоря о пьесах, навязанных Шекспиру, нельзя отделаться от весьма оригинальной и глубокой гипотезы Гордона Крэга, видящего в Шекспире еще совсем особую многоголосность и слышащего в его произведениях несколько авторских голосов. Все это чрезвычайно затемняет для нас понимание шекспировской полифонии. < ..>

Какие социальные факты отражались в Шекспировском полифонизме? Да в конце концов, конечно, те же, по главному своему существу, что и у Достоевского. Тот красочный и разбитый на множество сверкающих осколков Ренессанс, который породил и Шекспира и современных ему драматургов, был ведь, конечно, тоже результатом бурного вторжения капитализма в сравнительно тихую средневековую Англию. И здесь так же точно начался гигантский развал, гигантские сдвиги и неожиданные столкновения таких общественных укладов, таких систем сознания, которые раньше совсем не приходили друг с другом в соприкосновение» [13, с. 410-411]. На наличие подобных «позаимствований» и «переделок» из западноевропейской литературы, только уже в творчестве Достоевского, указывал и Л. Гроссман в «Поэтике Достоевского» [4].

Следует отметить, что во втором, переработанном и дополненном издании книги «Проблемы поэтики Достоевского» М.М. Бахтин мимо этих критических замечаний Луначарского не прошел. Возможно, в подтексте его «формальных возражений» сказывалось и ощущение более широких и глубоких областей соприкосновения двух гениев (думается, что и приведенное выше мнение Л.В. Пумпянского, во многом единомышленника М.М. Бахтина, подтверждает наш тезис).

На одной из таких «болевых точек» соприкосновения сосредоточивается и Л.С. Выготский в работе «Психология искусства» [1]. Рассуждая о характере творчества Достоевского и Шекспира, Л.С. Выготский приводит мнение Вл. Гиппиус, всецело солидаризируясь с ним: «Понимание Шекспира начинается там, где есть “трагическое сознание" <...>. Оно начинается с Толстого и Достоев- 
ского, - эти два писателя - первые у нас воистину шекспировской стихии, то есть воистину трагической», главное - Достоевский, потому что Толстой «был лишь отчасти трагиком» (его отношение глубоко интересный вопрос проблемы - Шекспир и Россия). «Они \{Достоевский и Шекспир - явления самые родственные: и в том и в другом дух Библии. Трагическая бездна переживается при чтении Шекспира не в сознании, а в ощущении, в ощущении художественном, как неосязаемые для мысли испарения почвы - или больше того - как ее еще несознанный состав. В таком усвоении, когда отыскивается бессознательная подпочва творческой мудрости, Шекспир мог явиться нам - уже после Ницше, после декадентства». И говоря о «роковых», или трагических страстях, порождаемых «древним хаосом родимым», Вл. Гиппиус продолжает: «Не человек владеет ими, а они владеют им - и несут его, и роняют, и возносят; и крутят и мечут человеческую волю. Таков и Гамлет, и Макбет, и Лир. Таков и Раскольников, и Рогожин, и Ставрогин, и Мышкин, и Карамазовы». Здесь еще Гамлет не выделен из круга Макбета и Лира. Но указание на близость героям Достоевского глубоко верное. Это тема особого исследования, манящая глубочайшими и неожиданными совпадениями. Здесь отдельные черты приводятся (и ниже). Гамлета можно сблизить не с Рудиным, а с Идиотом, с которым его роднит «иное бытие», грань между безумием и разумением, глубинная мистичность души, парализованность воли. А главное, есть в настроении этих образов, в их свете что-то близкое; со Свидригайловым (ниже), который называет себя мистиком и видит привидения; Ставрогиным (Булгаков С.Н.: «Ставрогин - мистик... медиум (курсив. - Л. В.)... одержимый»). Особенно его безволие и то, что его драма сдвинута в политическую (Иван Царевич); мать говорит о нем: «...он похож больше, чем на принца Гари, на принца Гамлета»; с Карамазовыми, где отдельные черточки разбросаны по всему роману, в его теме - отцовство, его мистическое начало, - трагедия Гамлета наоборот (в ходе событий “Идиота”); отчасти с Раскольниковым» [1, с. 541].

Как видно из приведенных цитат, в отличие от Л. Пумпянского, Л.С. Выготский считал, что Шекспира и Достоевского «сближает родственная им обоим стихия трагического», и в своей работе он подробно развивает эту мысль.

В частных суждениях Вл. Гиппиус, приведенных Л.С. Выготским, нам хотелось бы обратить особое внимание на следующее утверждение: «Не человек владеет ими (стихиями - Ф.М.), а они владеют им - и несут его, и роняют, и возносят; и крутят и мечут человеческую волю. Таков и Гамлет, и Макбет, и Лир. Таков и Раскольников, и Рогожин, и Ставрогин, и Мышкин, и Карамазовы». Это не просто красивая метафора, удачно найденная фигура речи. Воспринятая концептуально, она открывает новую перспективу для дальнейших исследований.

Профетизм Достоевского можно рассматривать как выражение стихийно-индивидологических установок в изображении героев, его ориентацию на изображение не типа, а по-пушкински сложной, противоречивой индивидуальности, корни которой уходят в шекспировскую традицию. Отсюда же и некая общность в обнаруживаемых исследователями профетических установках Достоевского и Шекспира. Достоевский, открывая в человеке «бездны», рисует их в сложном, напряженном, динамичном взаимодействии. Они, выражаясь метафорически, искривляют вокруг себя пространство, и в этих «стихийных завихрениях», как в болезненных состояниях, о которых упоминал Свидригайлов, проступают «обрывки миров иных». Полистихийность натуры, т.е. способность откликаться на различные, иногда противоположные интенции этих «силовых полей», - питательная основа для индивидологизации героев Достоевского.

\section{СПИСОК ИСТОЧНИКОВ И ЛИТЕРАТУРЫ}

1. Выготский Л.С. Психология искусства. Минск: Современное слово, 1968. 480 с.

2. Гончаров И.А. СС в 8 т. Т. 8. М.: Худ. лит., 1980. 560 с.

3. Гроссман Л.П. Библиотека Достоевского. По неизданным материалам. С приложением каталога библиотеки Достоевского. Одесса. Книгоиздательство А.А. Ивасенко, 1919. 167 с.

4. Гроссман Л.П. Поэтика Достоевского. Гос. академ. худож. наук., 1925. 191 с.

5. Достоевский Ф.М. ПСС в 30 т. Л.: Наука, 1972-1990.

6. Захаров Н.В. Вхождение Шекспира в русский культурный тезаурус // Знание. Понимание. Умение. № 1. 2007. C. 131-140.

7. Захаров Н.В. Шекспиризм русской классической литературы: тезаурусный анализ. М., Изд-во МГУ, 2008. $320 \mathrm{c.}$

8. Коган Г.Ф. Лекция Е.В. Тарле «Шекспир и Достоевский» // Известия АН СССР. Сер. литературы и языка. Т. 38 (5). М., Наука, 1979. С. 477-484. 
9. Контелева А.В. Шекспировские аллюзии в романе Ф.М. Достоевского «Идиот» // Вестник Нижегород. ун-та им. Н.И. Лобачевского. № 2. 2014. С. 199-203.

10. Криницын А. Шекспировские мотивы в романе Ф.М. Достоевского «Бесы» // К 60-летию проф. А.И.Журавлевой / Сб. науч. тр. М.: Наука, 1998. С. 161-173.

11. Левин Ю.Д. Достоевский и Шекспир // Достоевский. Материалы и исследования. Т. І. Л.: Наука, 1974. С. $108-134$.

12. Лотман Ю.М. О «реализме Гоголя» // Лотман Ю.М. О русской литературе. Статьи и исследования. История русской прозы. Теория литературы. СПб.: Искусство, 1997. С. 694-712.

13. Луначарский А.В. О «многоголосости» Достоевского // Ф.М. Достоевский в русской критике. М. Худ. лит., 1956. С. 403-429.

14. Марков Е.Л. Критические беседы. IV. Романист-психиатр (по поводу сочинений Достоевского) // «Русская речь». № 6. 1879. С. 171-381.

15. Материалы для жизнеописания Федора Михайловича Достоевского. Биография, письма и заметки из записной книжки Ф. М. Достоевского. СПб.: Тип. Суворина, 1883. 376 с.

16. «Отечественные записки». № 9. 1882.

17. Писарев Д.И. Борьба за жизнь // Достоевский в русской критике: Сб. статей. М. Худ. лит., 1956. С. $162-229$.

18. Пумпянский Л.В. Классическая традиция. М.: Языки русской культуры, 2000. 870 с.

19. Розанов В.В. На лекции о Достоевском. // URL: http://www.vehi.net/rozanov/dost3.html

20. Розенблюм Л. М. Творческая лаборатория Достоевского-романиста // Лит. наследство. Т. 77. М.: Наука, 1965. C. 7-56.

21. Салтыков-Щедрин М.Е. Светлов, его взгляды, характер и деятельность // Салтыков-Щедрин М.Е. ПСС в 20 т. Т. 9. М.: Худ. лит., 1970. С. 411-419.

22. «Современник». № 12, отд. II. 1866.

23. Туниманов В.А. Шекспировские мотивы в романе И.А. Гончарова «Обломов» // Туниманов В.А. Лабиринт сцеплений: избранные статьи. СПб. Изд-во Пушкинский дом, 2013. С. 445-457.

24. Шекспир и русская культура / Под ред. акад. М. П. Алексеева. М.-Л.: Наука. 1965. 823 с.

25. Энгельгардт. Б. Идеологический роман Достоевского // Ф.М. Достоевский. Статьи и материалы. Сб. 2. Под ред. А.С. Долинина. Л.-М.: Изд-во «Мысль», 1924. С. 71-109. URL: https://fotki.yandex.ru/next/users/aljokin/ album/209193/view/586153

Поступила в редакцию 10.06.2020

Макаричев Феликс Вячеславович, доктор филологических наук,

профессор кафедры иностранных языков

ФГБОУ ВО «Санкт-Петербургский государственный архитектурно-строительный университет»

190005, Россия, г. Санкт-Петербург, 2-я Красноармейская улица, 4

E-mail: spbfell@mail.ru

\section{F.V. Makarichev}

PROPHETIZM OF F.M. DOSTOEVSKY'S ART ATTITUDE AND ITS INFLUENCE ON POETICS OF HIS ARTISTIC IMAGES

DOI: $10.35634 / 2412-9534-2021-31-2-283-290$

The article reveals the interrelation and interdependence of F.M. Dostoevsky's prophetic intuitions with the peculiarities of methodology and, more broadly, the nature of the writer's artistic creativity. Comparative parallels are drawn between the artistic attitudes of Dostoevsky and Shakespeare in the reception of literary critics and philosophers in the early 20th century. This leads to the conclusion that Dostoevsky's prophetizm can be considered an expression of the spontaneous-individological principles in the representation of characters, the writer's orientation towards the representation not of a type, but of a Pushkin-like complex, contradictory individuality, which has its roots in the Shakespearean tradition.

Keywords: poetics, prophetic attitude, shakespearism, artistic image, tragedy, individology.

\section{REFERENCES}

1. Vygotskij L.S. Psihologija iskusstva [L.S. Vygotsky Psycology of Art]. Minsk, Sovremennoe slovo, 1968,480 p. (In Russian).

2. Goncharov I.A. SS v 8 t. T. 8 [I.A. Goncharov 8-volume edition of works, v. 8]. Moscow: Hud. lit., 1980,560 p. 
3. Grossman L.P. Biblioteka Dostoevskogo. Po neizdannym materialam. S prilozheniem kataloga biblioteki Dostoevskogo [L.P. Grossman Dostoevsky's Library]. Odessa. Knigoizdatel'stvo A.A. Ivasenko, 1919, 167 p. (In Russian).

4. Grossman L.P. Pojetika Dostoevskogo [L.P. Grossman Dostoevsky’s Poetics]. Gos. akadem. hudozh. Nauk, 1925, 191 p. (In Russian).

5. Dostoevskij F.M. PSS v 30 t. [F.M. Dostoevsky Complete works in thirty volumes]. Leningrad.: Nauka, $1972-1990$.

6. Zaharov N.V. Vhozhdenie Shekspira v russkij kul'turnyj tezaurus [N.V. Zaharov Shakespeare's entry into Russian Cultural Thesaurus]. Znanie. Ponimanie. Umenie. 2007, no. 1, pp. 131-140. (In Russian).

7. Zaharov N.V. Shekspirizm russkoj klassicheskoj literatury: tezaurusnyj analiz. [N.V. Zaharov Shakespearizm of Russian Classical Literature: Analysis Thesaurus] Moscow: Izd-vo MGU, 2008, 320 p. (In Russian).

8. Kogan G.F. Lekcija E.V. Tarle «Shekspir i Dostoevskij». [G.F. Kogan The Lecture of E.V.Tarle "Shakespeare and Dostoevsky"] Izvestija AN SSSR. Ser. literatury i jazyka [Izvestiya of the Academy of Sciences of the USSR Series Literature and Language]. T. 38 (5). Moscow: Nauka, 1979, pp. 477-484. (In Russian).

9. Konteleva A.V. Shekspirovskie alljuzii v romane F.M. Dostoevskogo «Idiot». [A.V. Kontelyova Allusions to Shakespeare in the novel "Idiot" by F.M. Dostoevsky] In: Vestnik Nizhegorod. un-ta im. N.I. Lobachevskogo, 2014, no. 2, pp.199-203. (In Russian).

10. Krinicyn A.B. Shekspirovskie motivy v romane F.M. Dostoevskogo «Besy». [A.B. Krinitsyn Shakespeare's motives in the novel "Demons" by F.M. Dostoevsky] In: K 60-letiju prof. A.I.Zhuravlevoj. Sb. nauch. tr. Moscow: Nauka, 1998, pp. 161-173. (In Russian).

11. Levin Ju.D. Dostoevskij i Shekspir. In: Dostoevskij. Materialy i is-sledovanija [Y.D. Levin Dostoevsky and Shakespeare. Dostoevsky: Materials and Research, V.1]. Leningrad: Nauka, 1974, pp. 108-134. (In Russian).

12. Lotman Ju.M. "O realizme Gogolja». Lotman Ju.M. O russkoj literature. Stat'i i issledovanija. Istorija russkoj prozy. Teorija literatury [Yu.M. Lotman About Realism of Gogol. Articles and Research. The History of Russian Prose. Theory of Literature]. St-Petersburgb.: Iskusstvo, 1997, pp. 694-712. (In Russian).

13. Lunacharskij A.V. O «mnogogolososti» Dostoevskogo. F.M. Dostoevskij v russkoj kritike [A.V. Lunacharsky About Dostoevsky’s “multi-voice”]. Moscow: Hud. lit., 1956, pp. 403-429. (In Russian).

14. Markov E.L. Kriticheskie besedy. IV. Romanist-psihiatr (po povodu sochinenij Dostoevskogo). «Russkaja rech'» [E.L. Markov Critical discussions. IV. Novelist-psychiatrist (in connection with works of Dostoevsky)]. 1879, pp. 171-381. (In Russian).

15. Materialy dlja zhizneopisanija Fedora Mihajlovicha Dostoevskogo. Biografija, pis'ma i zametki iz zapisnoj knizhki F.M. Dostoevskogo [Materials for Life-Story of Fyodor Mikhailovich Dostoevsky. Biography, Letters and Notes from F.M. Dostoevsky's Notebook]. St-Petersburgb: Tip. Suvorina, 1883. 376 p. (In Russian).

16. «Otechestvennye zapiski» [“Annals of the Fatherland”].1882, no. 9. (In Russian).

17. Pisarev D.I. Bor'ba za zhizn'. In: Dostoevskij v russkoj kritike: Sb. Statej [Struggle for existence. Dostoevsky in Russian Critics: collection of articles]. Moscow: Hud. lit., 1956, pp. 162-229. (In Russian).

18. Pumpjanskij L.V. Klassicheskaja tradicija [Classical Tradition]. Moscow: Jazyki russkoj kul'tury, 2000.870 p. (In Russian).

19. Rozanov V.V. Na lekcii o Dostoevskom [At the lecture on Dostoevsky]. URL: http://www.vehi.net/rozanov/ dost3.html

20. Rozenbljum L.M. Tvorcheskaja laboratorija Dostoevskogo-romanista. [Art laboratory of Dostoevsky as a novelist] Lit. nasledstvo. T. 77. Moscow: Nauka, 1965, p. 7-56. (In Russian).

21. Saltykov-Shhedrin M.E. Svetlov, ego vzgljady, harakter i dejatel'nost' . In: Saltykov-Shhedrin M.E. PSS v 20 t. T. 9. [Svetlov, his views, character and activities. M.Y. Saltykov-Shchedrin, The complete edition of works in 20 volumes, V. 9]. Moscow: Hud. lit., 1970, pp. 411-419.

22. «Sovremennik». ["The Contemporary"]. 12., otd. II. 1866.

23. Tunimanov V.A. Shekspirovskie motivy v romane I.A. Goncharova «Oblomov». Tunimanov V.A. Labirint sceplenij: izbrannye stat'i. [Shakespeare's motives in the novel "Oblomov" by I.A.Goncharov]. St-Petersburgb: Izdvo Pushkinskij dom, 2013, pp. 445-457. (In Russian)

24. Shekspir i russkaja kul'tura. [Shakespeare and Russian Culture]. Moscow-Leningrad: Nauka, 1965. 823 p. (In Russian)

25. Jengel'gardt B. Ideologicheskij roman Dostoevskogo. F.M. Dostoevskij. Stat'i i materialy. Sb. 2. Pod red. A.S. Dolinina. [Dostoevsky's Ideological Novel]. L.-Moscow: Izd-vo «Mysl'», 1924, pp. 71-109. (In Russian). URL: https://fotki.yandex.ru/next/users/aljokin/album/209193/view/586153

Makarichev F.V., Doctor of Philology, Professor at Department of Foreign Languages

Saint-Petersburg State University of Architecture and Civil Engineering

Vtoraya Krasnoarmeiskaya st., 4, Saint-Petersburg, Russia, 190005

E-mail: spbfell@mail.ru 